\title{
Noticeboard
}

\section{The Berkshire Conference of Women Historians 1984}

The theme of the sixth Berkshire Conference on the History of Women to be held June 1-3, 1984, at Smith College, Northampton, Mass. is 'Reassessing Our Past: Women's History after Fifteen Years'. The Program Committee welcomes proposals for sessions that discuss current debates in women's history, synthesize the state of knowledge, or identify new research directions. The Committee also encourages proposals for sessions on methodology that suggest ways of using, for example, legal records, material culture, women's religious reflections, domestic architecture, portraiture etc, to explain women's historical experience.

The Committee strongly encourages proposals for complete sessions involving no more than two papers and two commentators (one of whom may be the chair). Individual papers will also be considered. Proposals should include: the title of the papers; names, addresses, and brief vitae of all participants (with their affiliations or place of residence); and one-page abstracts of the papers. Each proposal will be reviewed by two members of the Program Committee. Send three copies of the proposal to either Carol Groneman, History Department, John Jay, College, $445 \mathrm{~W}$. 59St. NY, NY. 10019 or Mary Beth Norton, History Department, McGraw Hall, Cornell University, Ithaca, NY 14853 USA. Enclose a stamp addressed postcard which will be returned upon receipt of the proposal. The first deadline for submission is December 1,1982 and the final deadline is March 151983.

\section{Research on Lesbians over 65}

Monika Kehoe, Ph.D. a research associate at San Francisco State University, in CERES (Center for Research and Education in Sexuality) is to survey the status of lesbians over 65 years of age in the United States, and would welcome information about any comparable enquiry in the UK. Replies to: CERES, San Francisco State University, San Francisco, Ca. 94132, USA. 